\title{
A Low VSWR and High Efficiency Waveguide Feed Antenna Array
}

\author{
Zhao Xiao-Fang $\mathbb{D}^{1},{ }^{1}$ Liu Hua-Zhu $\mathbb{D}^{1},{ }^{1}$ Li Yi, ${ }^{1}$ \\ Zhou Shi-Gang, ${ }^{2}$ and Chow-Yen-Desmond Sim (iD $^{3}$ \\ ${ }^{1}$ School of Electrical Engineering \& Intelligentization, Dongguan University of Technology, Dongguan 52380, China \\ ${ }^{2}$ School of Electronics and Information, Northwestern Polytechnical University, Xian 710072, China \\ ${ }^{3}$ Department of Electrical Engineering, Feng Chia University, Taichung, Taiwan \\ Correspondence should be addressed to Liu Hua-Zhu; 654650052@qq.com
}

Received 11 December 2017; Accepted 31 March 2018; Published 13 May 2018

Academic Editor: Mingjian Li

Copyright (C) 2018 Zhao Xiao-Fang et al. This is an open access article distributed under the Creative Commons Attribution License, which permits unrestricted use, distribution, and reproduction in any medium, provided the original work is properly cited.

\begin{abstract}
A low VSWR and high efficiency antenna array operating in the Ku band for satellite communications is presented in this paper. To achieve high radiation efficiency and broad enough bandwidth, all-metal radiation elements and full-corporate waveguide feeding network are employed. As the general milling method is used in the multilayer antenna array fabrication, the $E$-plane waveguide feeding network is adopted here to suppress the wave leakage caused by the imperfect connectivity between adjacent layers. A $4 \times 8$ elements array prototype was fabricated and tested for verification. The measured results of proposed antenna array show bandwidth of $6.9 \%(13.9-14.8 \mathrm{GHz})$ for VSWR $<1.5$. Furthermore, antenna gain and efficiency of higher than $22.2 \mathrm{dBi}$ and $80 \%$ are also exhibited, respectively.
\end{abstract}

\section{Introduction}

Slotted waveguide antenna array has the advantages such as high power capacity, low transmission loss, and low cross-polarization level. Thus, it is widely used in radar and communication systems [1-3]. However, one of the main drawbacks of conventional slotted waveguide antenna array is its inherently narrow bandwidth because of the longline effect, and the bandwidth would become narrower with increasing array size. The other drawback of the slotted waveguide antenna arrays is the high fabrication cost, because specialized fabrication technique such as dip-brazing is always applied during the fabricating process.

Recently, corporate-feed hollow-waveguide slot arrays in millimeter wave $(\mathrm{mmW})$ band with multilayer structures have been reported [4-7], and by applying the corporatefeed method, impedance bandwidths of $8 \%$ to $12 \%$ (at VSWR <2) can be obtained without exhibiting any beam squint. An efficient antenna fabrication method known as diffusion bonding is used in the antenna array fabrication, and up to $80 \%$ of radiation efficiency can be achieved. However, because it is difficult to achieve high-temperature and uniform pressure during the manufacturing process for a largescale array, this unique fabrication method is not suitable for array fabrication in the "lower" frequency band, such as those in the Ku band. Therefore, a multilayer corporatefeed slot antenna array was proposed and fabricated by using simple milling process [8-10]. Nonetheless, the wave leakage between layers of this reported antenna array cannot be avoided, because the feeding network used here is an $\mathrm{H}$-plane waveguide type.

Recently, a number of antenna array designs working in the $\mathrm{Ku}$ band with waveguide feed network have also been reported for satellite system applications [11-15]. Even though all these antenna array designs have been successfully reported, however, they have exhibited certain disadvantages that may compromise the performances. For example, the microstrip antenna element and waveguide feed network have been applied in [11, 12], and they have exhibited element loss and results in lower efficiency. Even though the coupling between elements in [13] is strong, however, that will reduce the performances of the antenna array when the 


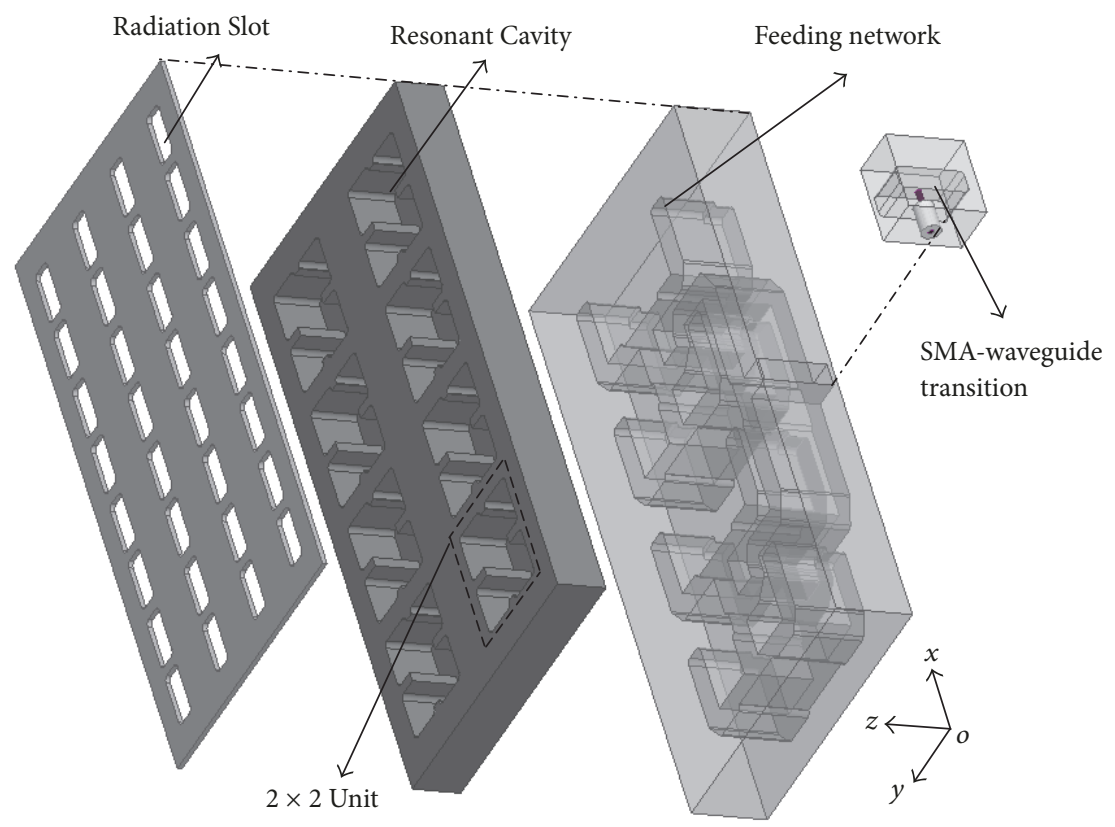

FIGURE 1: Geometry of proposed antenna array in three-dimensional view.

array gets larger. The other disadvantage of this design is its complex structure; thus mass producing this array will be very difficult. In [14], the connected-dipole active array is presented, and when the element is used as passive array fed by a microstrip network, the efficiency will not be high. In [15], the continuous transverse stub array is proposed for satellite communication; however, the structure is also very complicated, and it is not very suitable for small size array design.

Therefore, in this paper, an aperture size $110 \times 55 \mathrm{~mm}^{2}$ corporate-feed slot antenna array with $E$-plane waveguide feeding network is presented. The proposed antenna array is composed of three layers, namely, radiating slots layer, cavity layer, and a feeding network layer. Here, E-plane waveguide feeding network is used to reduce wave leakage considering there are gaps between adjacent layers in real fabrication. An antenna prototype is fabricated by applying the simple milling process. Experimental results show that the proposed antenna exhibits low VSWR and high radiation efficiency $(>80 \%)$ characteristics. Details of the antenna design and measurement results are shown in the following sections.

\section{Antenna Array Configuration and Design}

Figure 1 shows the three-dimensional (3D) view of proposed antenna array structure. The antenna array is a multilayer type composed mainly of three layers, namely, the antenna radiation slots, resonant cavity, and feeding network, from top to bottom, respectively. The $2 \times 2$ element subarrays employed as one unit here are for the purpose of minimizing the occurrence of grating lobe as much as possible $[4,8]$. The design of feeding network adopts the $E$-plane waveguide type, so that wave leakage can be prevented after the assembly.
There is also a SMA-waveguide transition at one side to convert the waveguide port to SMA port.

Figure 2 shows the $2 \times 2$ subarray configuration with related structural parameters, and it is also comprised of three parts. The working mechanisms of the proposed subarray are as follows: (1) the energy is coupled from the $E$-plane waveguide at the bottom layer to the resonant cavity located at the middle layer via the coupling slot; (2) there are two pairs of side walls in the cavity for the purpose of splitting the resonant higher mode, which is similar to those reported in $[4,8]$; (3) the $2 \times 2$ radiation slots on the top share the same resonant cavity. Due to the fact that the higher mode resonant can also be excited, the radiation slots can be equally excited. Here, the simulated $E$-field distributions at the top of radiation slot and in the middle and bottom of the resonant cavity are shown in Figure 3. At the bottom waveguide layer, a small notch $\left(c_{l} \times c_{h}\right)$ is loaded at one corner of the waveguide, and a distance $d_{f}$ separates the coupling slot and the waveguide edge. Notably, both parameters are implemented for impedance matching of the antenna.

To fully develop and transform the $2 \times 2$ subarray into a larger array antenna type, proper $E$-plane corporate-feednetwork is therefore required. However, the full-corporate $E$-plane waveguide feeding networks cannot be simply composed by $H$-junctions and $T$-junctions as reported in $[4,8]$, because the output ports of T-shaped $E$-plane waveguide junctions are excited out-of-phase. Figure 4 presents the configuration of proposed full-corporate $E$-plane waveguide feeding networks for the $4 \times 8$ array, and Table 1 gives the full detailed dimensions of the antenna array. It can be seen that, due to space limitation, some of the waveguide bends and junctions are carefully routed. It is also noteworthy that the surface roughness of each mechanic layer is not very 
TABLE 1: Dimension parameters for the antenna array (Unit: $\mathrm{mm}$ ).

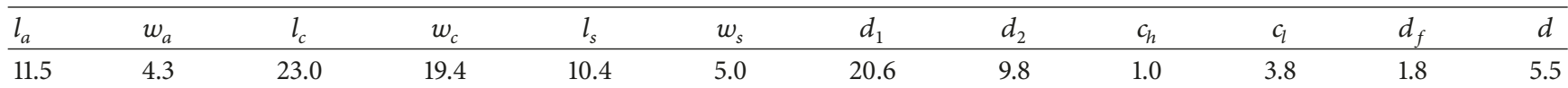

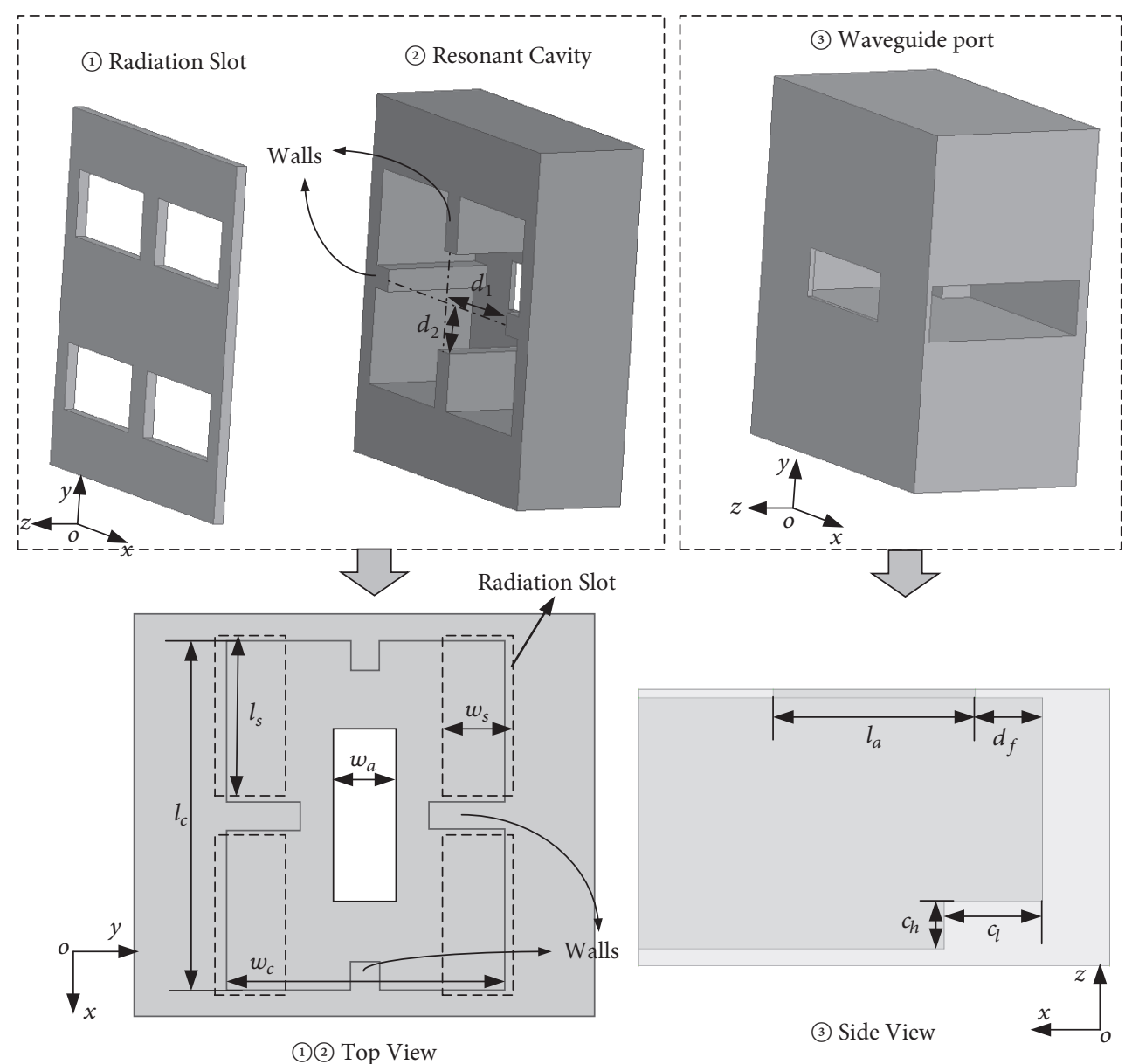

Figure 2: Configuration of the $2 \times 2$ subarray element [16].

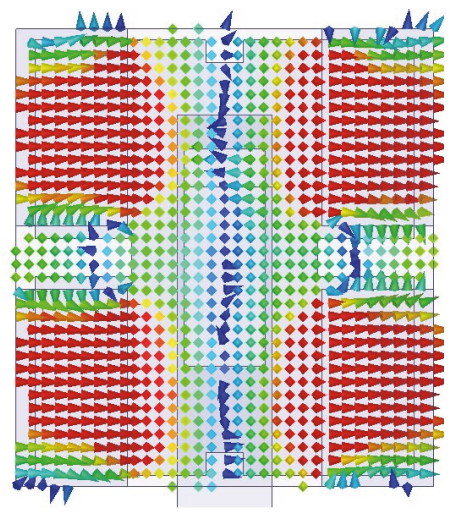

Top of the

radiation slot

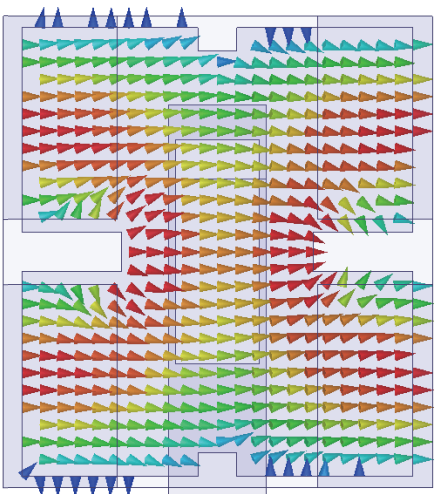

Middle of the resonant cavity

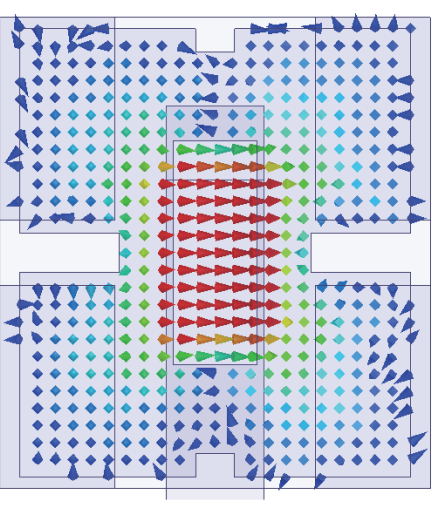

$E$ Field (V_per_m)

$2.0000 \mathrm{e}+003$
$1.8571 \mathrm{e}+003$ $1.8571 \mathrm{e}+003$
$1.7143 \mathrm{e}+003$ $1.7143 \mathrm{e}+003$
$1.5714 \mathrm{e}+003$ $1.4286 \mathrm{e}+003$ $1.2857 \mathrm{e}+003$ $1.1429 \mathrm{e}+003$ $1.1429 \mathrm{e}+003$
$1.0000 \mathrm{e}+003$ $8.5714 \mathrm{e}+002$ $8.5714 \mathrm{e}+002$
$7.1429 \mathrm{e}+002$ $7.1429 \mathrm{e}+002$
$5.7143 \mathrm{e}+002$ $4.2857 \mathrm{e}+002$ $2.8571 \mathrm{e}+002$ $1.4286 \mathrm{e}+002$ $0.0000 \mathrm{e}+000$

Figure 3: Simulated E-field distribution. 


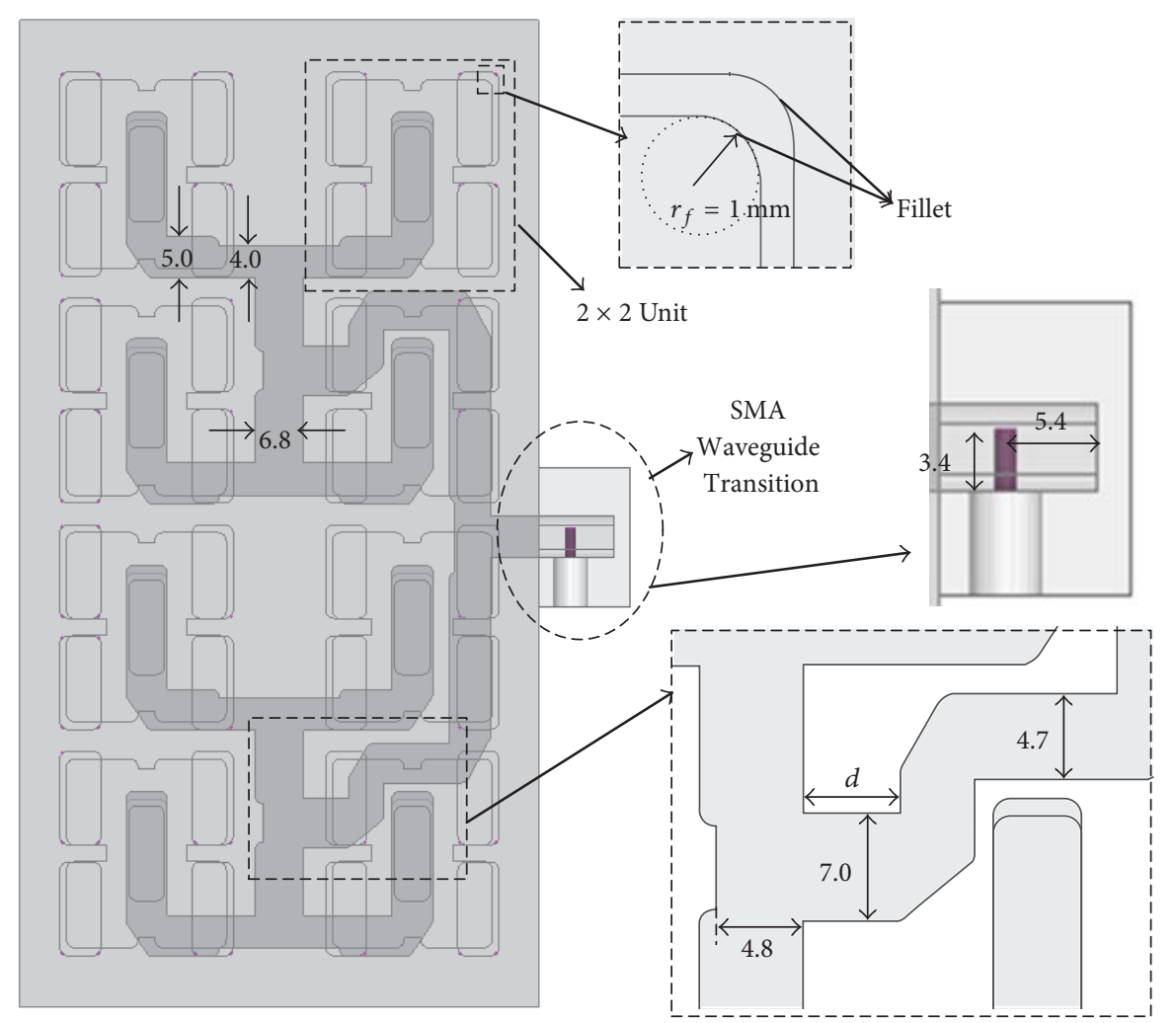

FIgURE 4: Complete $E$-plane waveguide feed-networks of the $4 \times 8$ array.

strict in this work, and thus it is not necessary to use more screws to press two layers very hard together. These factors have therefore contributed to the advantages of this proposed antenna (ease in fabrication), yielding lower fabrication cost.

\section{Design Evolution and Parametric Studies}

To further comprehend the design of this antenna, some of the vital parameters such as $l_{s}, w_{s}$, and $d_{f}$ are analyzed and presented. The simulated VSWRs of the $2 \times 2$ subarray by tuning the length $\left(l_{s}\right)$ and width $\left(w_{s}\right)$ of radiation slot are given in Figures 5 and 6, respectively. As depicted in Figure 5, tuning $l_{s}$ between 9.9 and $11.9 \mathrm{~mm}$ can affect the impedance bandwidth of the upper and lower operating frequencies at along VSWR $<1.5$ threshold, even though the two resonances at approximately 13.9 and $14.5 \mathrm{GHz}$ are nearly unaffected. In this case, optimum $l_{s}$ is chosen to be $10.4 \mathrm{~mm}$, because it can give desirable bandwidth of approximately $13.67-14.68 \mathrm{GHz}$ (along VSWR $<1.5$ ) and exhibit better impedance matching for the two resonances. As shown in Figure 6, an increase in width $w_{s}$ by $1 \mathrm{~mm}$ (from 4 to $6 \mathrm{~mm}$ ) will results in shifting the lower resonance to lower frequency band (approximately $14.3 \mathrm{GHz}$ to $13.73 \mathrm{GHz}$ ). In addition, tuning $w_{s}$ will also highly affect the operating impedance bandwidth. Here, optimum $w_{s}$ is chosen to be $5 \mathrm{~mm}$, because it exhibits the widest VSWR $<1.5$ bandwidth. Besides tuning the radiation slot $w_{s}$, the simulated results in Figure 7 show that varying distance $d_{f}$ (from 0.8 to $2.8 \mathrm{~mm}$ ) can also exhibit similar resonant

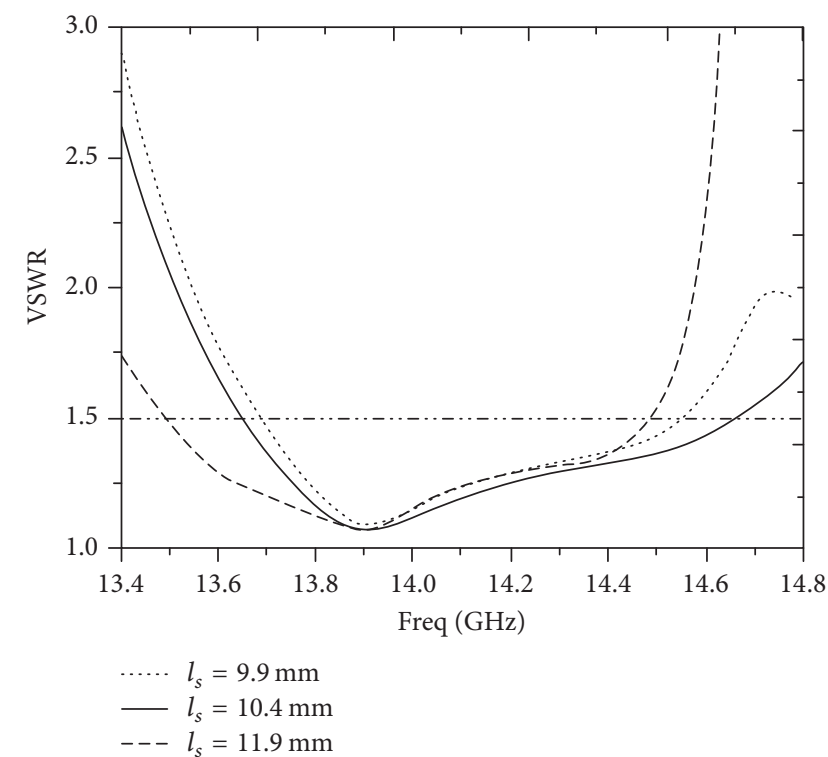

FIGURE 5: Simulated VSWR, varying $l_{s}$.

frequency shifting from approximately $14.3 \mathrm{GHz}$ to $13.7 \mathrm{GHz}$. Thus, in this case, the optimum $d_{f}$ chosen is $1.8 \mathrm{~mm}$.

\section{Simulated and Measured Results}

The $4 \times 8$ antenna array design was analyzed by using commercial simulator Ansoft HFSS. The parameters shown 


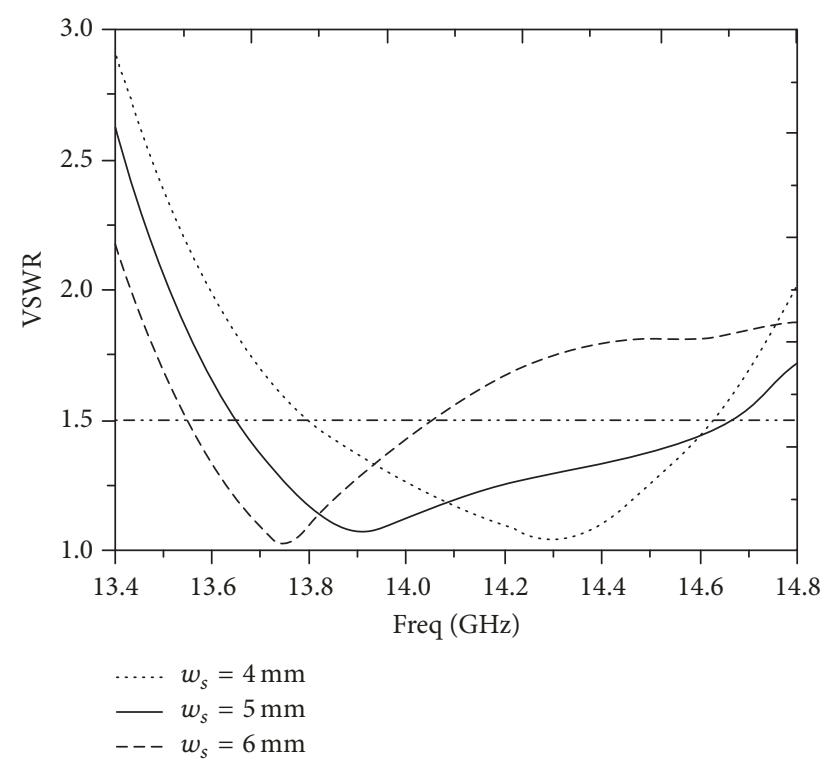

FIGURE 6: Simulated VSWR, varying $w_{s}$.

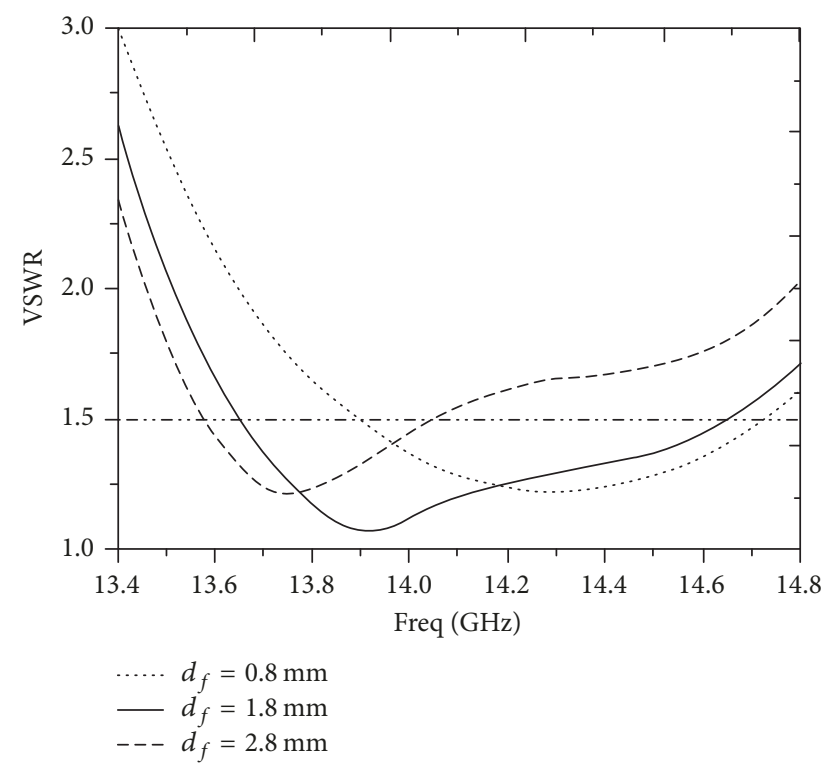

FIGURE 7: Simulated VSWR, varying $d_{f}$.

in Figures 2 and 4 are optimized and the final dimensions are listed in Table 1. Milling technique was applied in this case to fabricate the antenna prototype. As shown in Figure 8, the material used for this prototype antenna is aluminum. Notably, the layer partition of the actual mechanical model is slightly different from the layers shown in Figure 2. This is because in order to suppress the wave leakage between adjacent layers, the waveguides are intentionally split in the middle of the $E$-plane of corporate-feed-networks, in which minimal current flow can be attained, so that the gaps caused by the partition and tight electric-contact among the metallic layers are not critical [9].

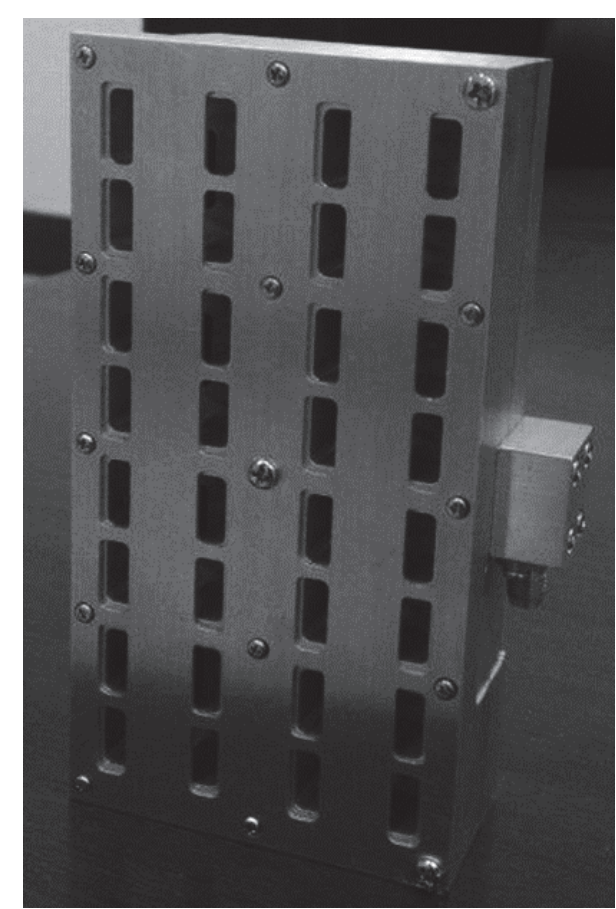

Figure 8: Photo picture of proposed antenna array.

The VSWR of the antenna prototype was measured by Agilent N5224A network analyzer. The measured and simulated VSWR results are shown in Figure 9, and good agreement can be observed. For a low VSWR of less than 1.5 (VSWR < 1.5), the measured bandwidth of proposed antenna array was $6.9 \%(13.9-14.8 \mathrm{GHz})$. The radiation patterns were measured in a far field range anechoic chamber. The simulated and measured radiation patterns in both $E$ plane and $H$-plane of proposed antenna array at $14.5 \mathrm{GHz}$ (center frequency) are shown in Figure 10. Good validation between the simulated and measured pattern is also observed. In this figure, it is realized that the side lobe level (SLL) is not very low (approximately $-14 \mathrm{~dB}$ ), because each element of the array has exhibited uniform excitation. If lower SLL is required, the tapered distribution (such as Taylor and Chebyshev distribution) technique can be used in the array design. Notably, this technique has been studied in [10], in which an unequal power divided $T$-junction was applied in the feeding network. However, the use of this technique will increase the manufacturing difficulty of this work, which is not favourable in this case.

The realized gain of proposed antenna array was measured by applying the conventional gain-comparison method [4]. Figure 11 shows the simulated and measured realized gain and efficiency of proposed antenna array. In this figure, stable gain variations between $22.2 \mathrm{dBi}$ and $22.9 \mathrm{dBi}$ over the operating bandwidth (VSWR < 1.5) of $13.9-14.8 \mathrm{GHz}$ were measured. Here, the measured gains are approximately $0.2-0.8 \mathrm{~dB}$ lower than the simulated ones. High aperture efficiency of more than $80 \%$ is also achieved over the same 
TABLE 2: Performance comparison between this work and reference antennas.

\begin{tabular}{|c|c|c|c|c|c|c|c|}
\hline Ref & Aperture size $\left(\mathrm{mm}^{2}\right)$ & Freq. (GHz) & BW (\%) & VSWR & Eff. (\%) & MP & Cost \\
\hline [4] & $75 \times 76$ & $58.8-63.9$ & 8.3 & $<1.5$ & $>80$ & Hard & High \\
\hline [8] & $146 \times 146$ & $14.5-16.1$ & 14.8 & $<2.0$ & $>80$ & Medium & Low \\
\hline [11] & $40 \times 366$ & $12.2-12.7$ & $4.0^{*}$ & $\mathrm{NA}$ & $>63$ & Easy & Low \\
\hline$[12]$ & $707 \times 182$ & $10.8-12.7$ & 16.5 & $<2.0$ & $>57$ & Easy & Low \\
\hline [13] & $35 \times 35$ & $12-15$ & 21 & $<2.0$ & $>70$ & Hard & Low \\
\hline [15] & $229.52 \times \pi$ & $26-40$ & 40 & $<2.0$ & $>80$ & Hard & High \\
\hline This work & $110 \times 55$ & $13.9-14.8$ & 6.9 & $<1.5$ & $>80$ & Easy & Low \\
\hline
\end{tabular}

${ }^{*}$ Axial Ratio bandwidth, NA: not applicable.

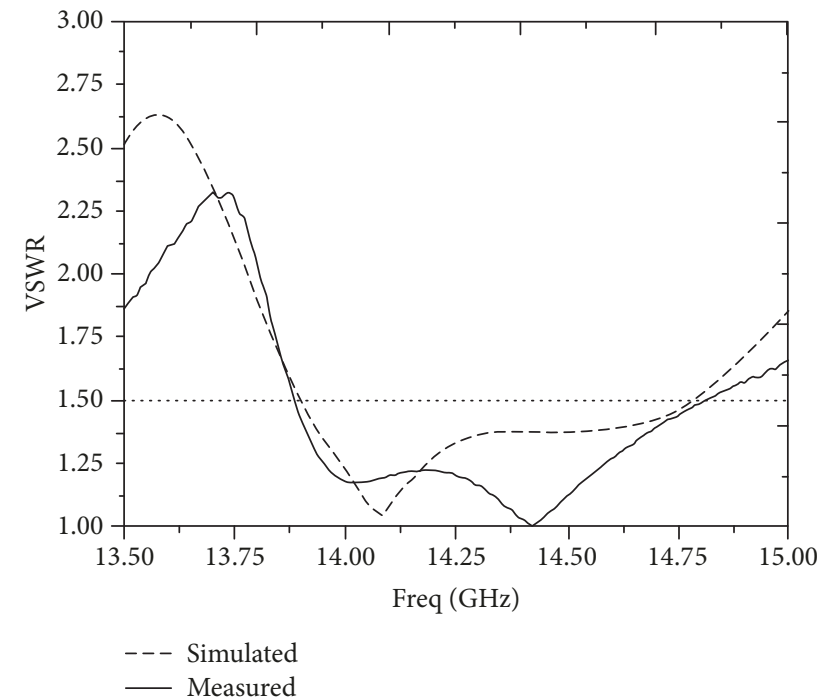

FIGURE 9: Simulated and measured VSWR of proposed antenna array.

operating band (13.9-14.8 GHz), and it can be up to $90 \%$ at some frequency points.

Table 2 shows the comparison of performances between the proposed antenna array (this work) and those relevant reported antenna arrays that are also operating in the $\mathrm{Ku}$ band. Even though the operating bandwidth of proposed one may have narrower bandwidth than that of $[4,8,12]$, by further observing this table, the proposed antenna offers very high radiation efficiency of over $80 \%$ in the $\mathrm{Ku}$ band (with milling process). From this table, one of the main advantages (novelty) of this proposed work is its ease in fabrication, thus leading to lower manufacturing cost during mass production.

\section{Conclusion}

A multilayer slot antenna array with $4 \times 8$ elements has been successfully proposed in the $\mathrm{Ku}$ band. Full-corporate feednetwork is used in this case to achieve desirable bandwidth of $6.9 \%$ (VSWR < 1.5) without beam squints. In addition, $E$-plane waveguide is also adopted to prevent wave leakage, which in turn can achieve high radiation efficiency of more than $80 \%$, even though the milling fabrication process was
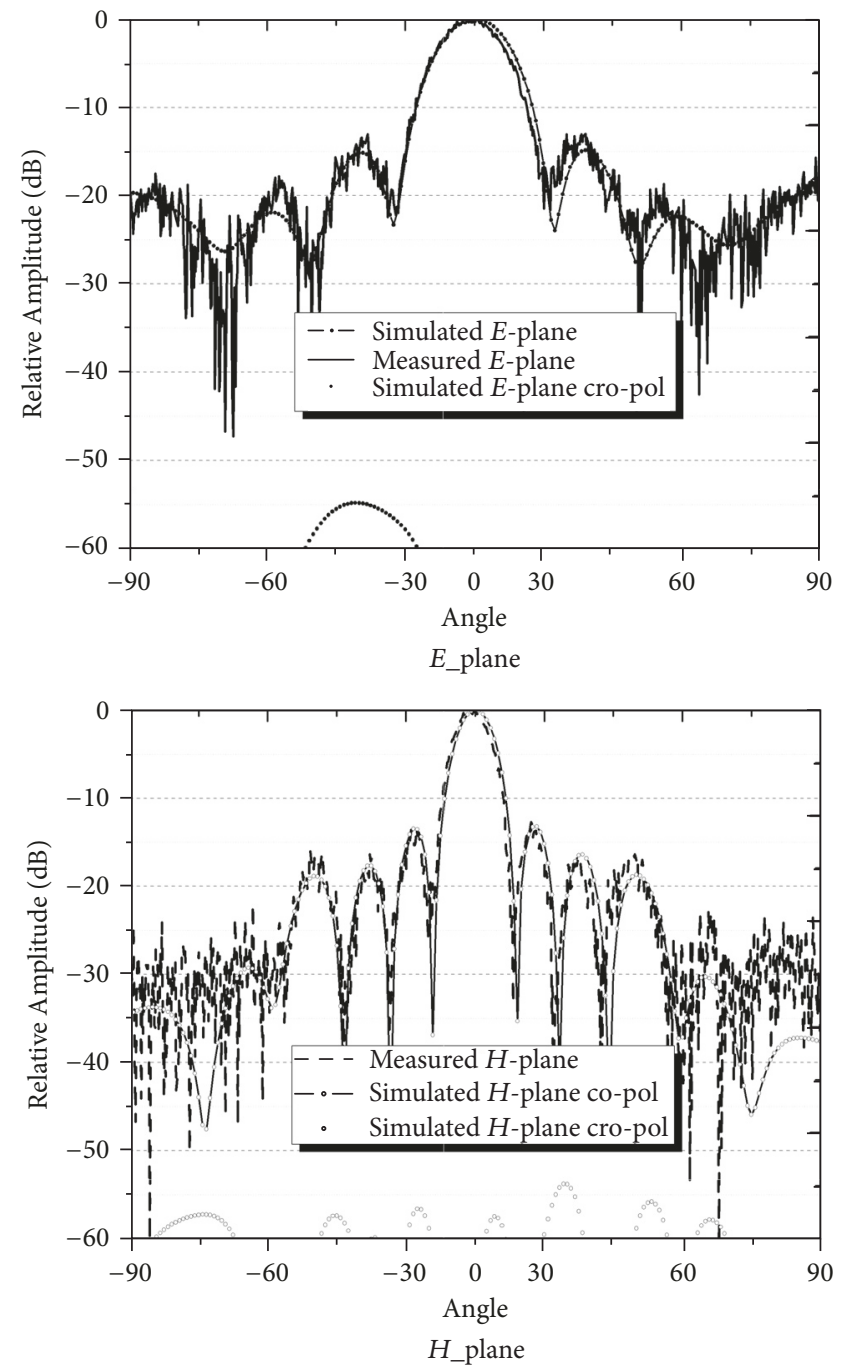

FIGURE 10: Simulated and measured patterns of proposed antenna array [17].

taken into consideration. Due to its compact aperture size and good efficiency, this proposed antenna array is a good candidate for $\mathrm{Ku}$ band satellite communications.

\section{Conflicts of Interest}

There are no conflicts of interest related to this paper. 


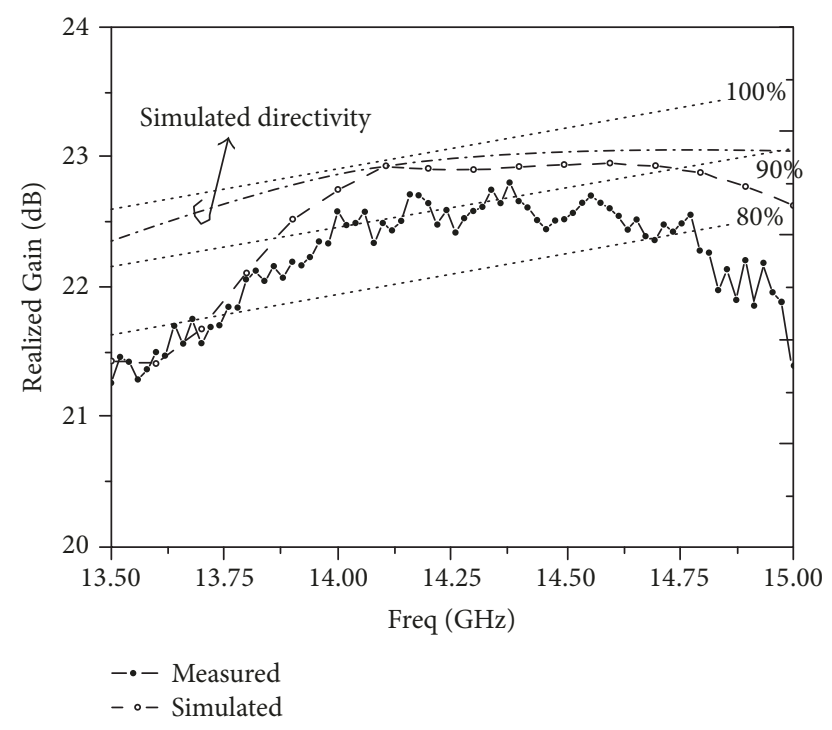

FIGURE 11: Simulated and measured gain and efficiency of proposed antenna array.

\section{Acknowledgments}

This work was supported by the Science and Technology Project of Guangdong Province under Grant nos. 2015A010103019 and 2017A010101038.

\section{References}

[1] X. Lu, S. Gu, X. Wang, H. Liu, and W. Lu, "Beam-scanning continuous transverse stub antenna fed by a ridged waveguide slot array," IEEE Antennas and Wireless Propagation Letters, vol. 16, pp. 1675-1678, 2017.

[2] W.-J. Gao, J.-J. Jiao, Y.-Z. Han, Y.-K. Deng, Y.-H. Xiong, and X.M. Liu, "A compact broadband ridgedsquare-waveguide radiating element for phased array antennas in synthetic aperture radar applications," Microwave and Optical Technology Letters, vol. 54, no. 3, pp. 829-833, 2012.

[3] L. Zhang, Y.-C. Jiao, T. Ni, and W.-L. Liang, "Wideband circularly polarized planar monopole antenna for wireless communication applications," International Journal of Applied Electromagnetics and Mechanics, vol. 49, no. 3, pp. 427-434, 2015.

[4] Y. Miura, J. Hirokawa, M. Ando, Y. Shibuya, and G. Yoshida, "Double-layer full-corporate-feed hollow-waveguide slot array antenna in the 60-GHz band," IEEE Transactions on Antennas and Propagation, vol. 59, no. 8, pp. 2844-2851, 2011.

[5] C. Cui, S.-K. Kim, R. Song, J.-H. Song, S. Nam, and B.-S. Kim, "A 77-GHz FMCW radar system using on-chip waveguide feeders in 65-nm CMOS," IEEE Transactions on Microwave Theory and Techniques, vol. 63, no. 11, pp. 3736-3746, 2015.

[6] H. R. Jha and S. N. Singh, "A high-gain and high-bandwidth waveguide fed longitudinal slot doublets array antenna for Xband," AEÜ - International Journal of Electronics and Communications, vol. 70, no. 12, pp. 1622-1629, 2016.

[7] C. Wu, C. Lu, and W. Cao, "Wideband dual-polarization slot antenna with high isolation by using microstrip line balun feed," IEEE Antennas and Wireless Propagation Letters, vol. 16, pp. 1759-1762, 2017.
[8] H. Guan-Long, Z. Shi-Gang, C. Tan-Huat, and Y. Tat-Soon, "Broadband and high gain waveguide-fed slot antenna array in the Ku-band," IET Microwaves, Antennas \& Propagation, vol. 8, no. 13, pp. 1041-1046, 2014.

[9] G.-L. Huang, S.-G. Zhou, and T.-H. Chio, "Waveguide-Fed Cavity Backed Slot Antenna Array with high efficiency in the Ku-band," in Proceedings of the Joint 2012 IEEE International Symposium on Antennas and Propagation and USNC-URSI National Radio Science Meeting, APSURSI 2012, Chicago, Ill, USA, July 2012.

[10] G.-L. Huang, S.-G. Zhou, T.-H. Chio, H.-T. Hui, and T.-S. Yeo, "A low profile and low sidelobe wideband slot antenna array feb by an amplitude-tapering waveguide feed-network," IEEE Transactions on Antennas and Propagation, vol. 63, no. 1, pp. 419-423, 2015.

[11] M. Shahabadi, D. Busuioc, A. Borji, and S. Safavi-Naeini, "Low-cost, high-efficiency quasi-planar array of waveguide-fed circularly polarized microstrip antennas," IEEE Transactions on Antennas and Propagation, vol. 53, no. 6, pp. 2036-2043, 2005.

[12] M. M. Bilgic and K. Yegin, "Low profile wideband antenna array with hybrid microstrip and waveguide feed network for $\mathrm{Ku}$ band satellite reception systems," IEEE Transactions on Antennas and Propagation, vol. 62, no. 4, pp. 2258-2263, 2014.

[13] A. U. Zaman and P.-S. Kildal, "Wide-band slot antenna arrays with single-layer corporate-feed network in ridge gap waveguide technology," IEEE Transactions on Antennas and Propagation, vol. 62, no. 6, pp. 2992-3001, 2014.

[14] R. J. Bolt, D. Cavallo, G. Gerini et al., "Characterization of a dual-polarized connected-dipole array for ku-band mobile terminals," IEEE Transactions on Antennas and Propagation, vol. 64, no. 2, pp. 591-598, 2016.

[15] M. Ettorre, F. F. Manzillo, M. Casaletti, R. Sauleau, L. Le Coq, and N. Capet, "Continuous transverse stub array for ka-band applications," IEEE Transactions on Antennas and Propagation, vol. 63, no. 11, pp. 4792-4800, 2015.

[16] S.-G. Zhou, P. Dong, G.-L. Huang, C.-Y. Sim, and J.-Y. Li, "Wideband antenna array with full metal structure and air-filled microstrip feeding network," IEEE Transactions on Antennas and Propagation, vol. 65, no. 6, pp. 3041-3048, 2017.

[17] Y. Wang and Z. Du, "Dual-polarized slot-coupled microstrip antenna array with stable active element pattern," IEEE Transactions on Antennas and Propagation, vol. 63, no. 9, pp. 42394244, 2015. 


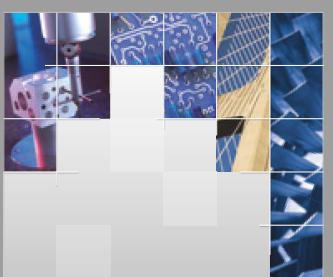

\section{Enfincering}
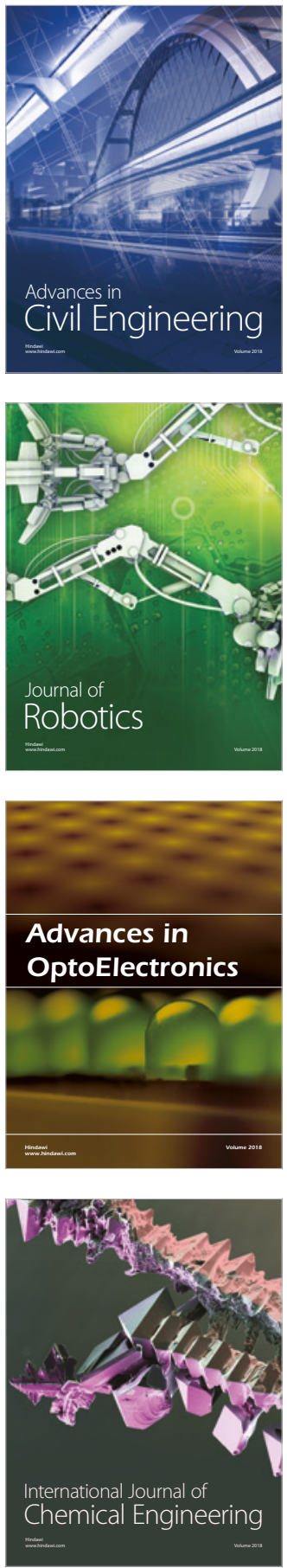

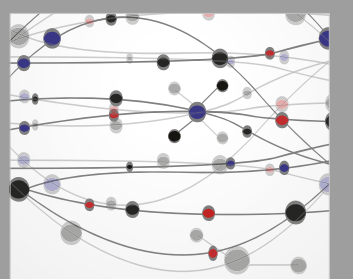

\section{Rotating \\ Machinery}

The Scientific World Journal

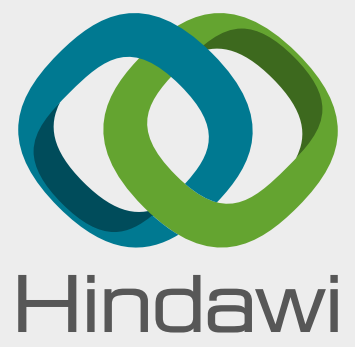

Submit your manuscripts at

www.hindawi.com
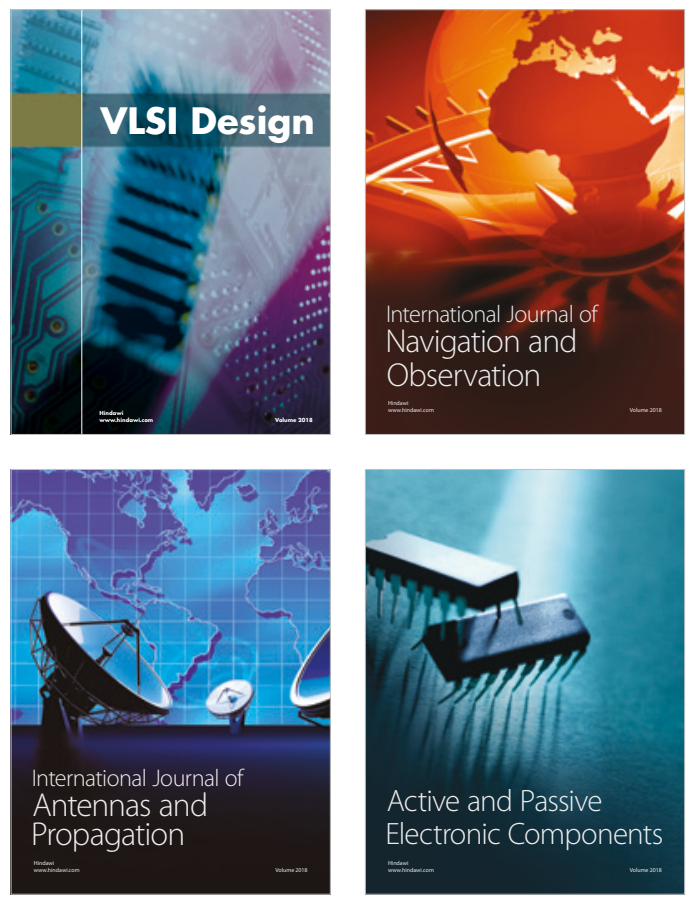
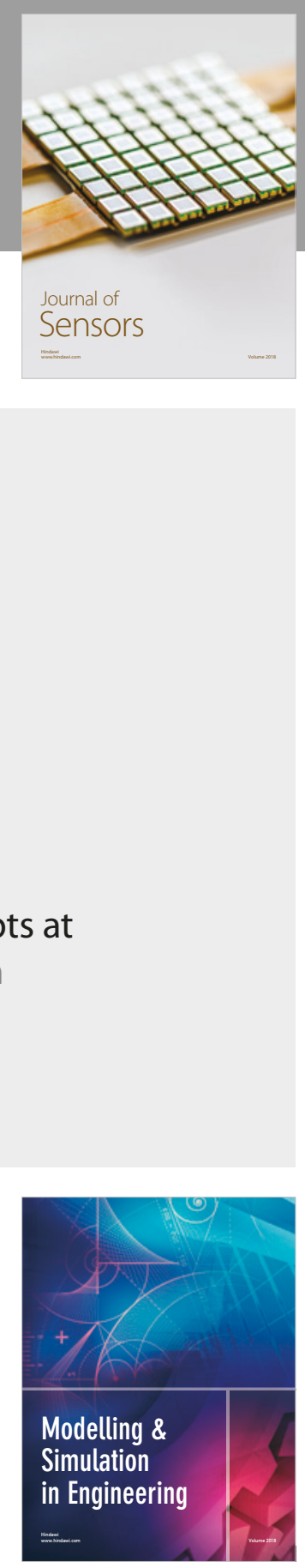

\section{Advances \\ Multimedia}
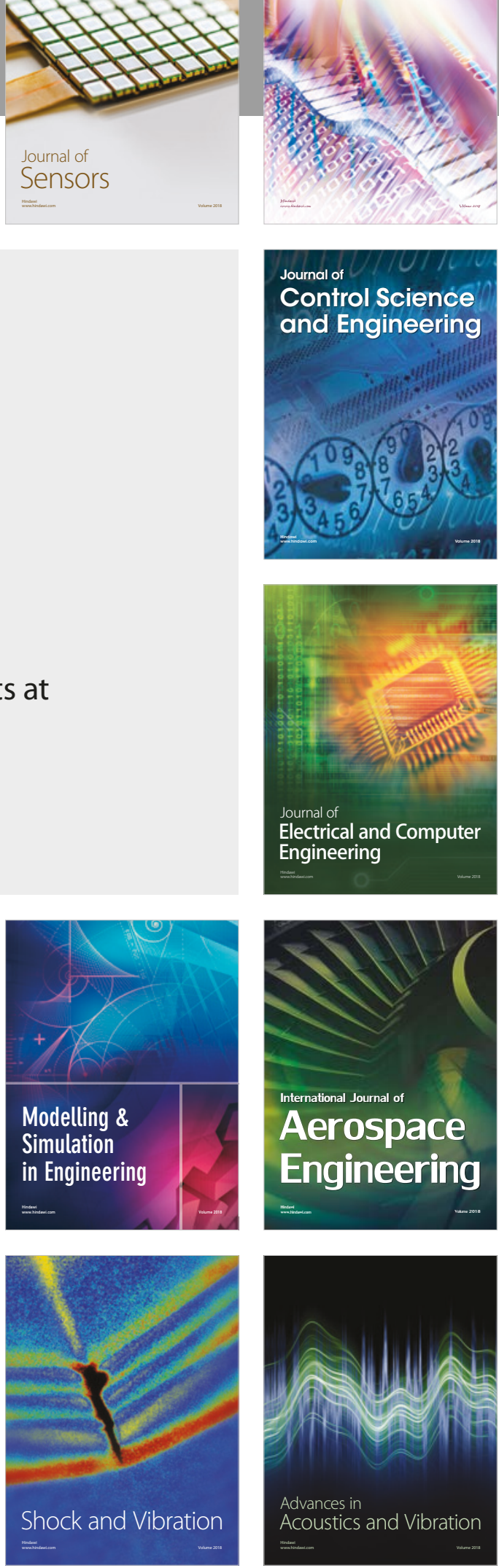